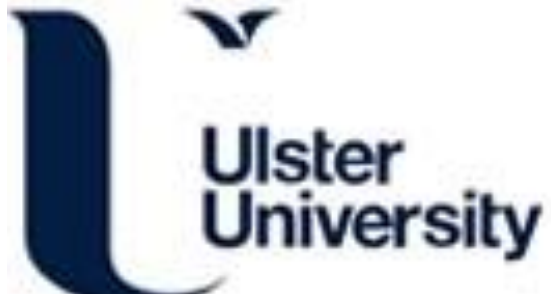

How can the social theory of Pierre Bourdieu assist sport management research?

Kitchin, P. J., \& Howe, P. D. (2013). How can the social theory of Pierre Bourdieu assist sport management research? Sport Management Review, 16(2), 123-134. https://doi.org/10.1016/j.smr.2012.09.003

Link to publication record in Ulster University Research Portal

Published in:

Sport Management Review

Publication Status:

Published (in print/issue): 01/09/2013

DOI:

10.1016/j.smr.2012.09.003

Document Version

Publisher's PDF, also known as Version of record

\section{General rights}

Copyright for the publications made accessible via Ulster University's Research Portal is retained by the author(s) and / or other copyright owners and it is a condition of accessing these publications that users recognise and abide by the legal requirements associated with these rights.

\section{Take down policy}

The Research Portal is Ulster University's institutional repository that provides access to Ulster's research outputs. Every effort has been made to ensure that content in the Research Portal does not infringe any person's rights, or applicable UK laws. If you discover content in the Research Portal that you believe breaches copyright or violates any law, please contact pure-support@ulster.ac.uk. 
Review

\title{
How can the social theory of Pierre Bourdieu assist sport management research?
}

\author{
P.J. Kitchin ${ }^{\text {a,* }}$, P. David Howe ${ }^{\text {b,1 }}$ \\ ${ }^{a}$ Ulster Sports Academy, University of Ulster, Shore Road, Newtownabbey, County Antrim, Northern Ireland BT370QB, United Kingdom \\ ${ }^{\mathrm{b}}$ School of Sport, Exercise and Health Sciences, Loughborough University, Loughborough, England LE11 3TU, United Kingdom
}

\section{A R T I C L E I N F O}

\section{Article history:}

Received 20 February 2012

Received in revised form 10 September 2012

Accepted 29 September 2012

\section{Keywords:}

Bourdieu

Practice-theory

Social capital

Organizational field

Organizational habitus

Ethnography

\begin{abstract}
A B S T R A C T
Currently there are some key issues that highlight the negative underbelly of sport and of those who manage it. Entrenched gender and racial inequality, corruption, and the marginalization of individuals and groups from organized sport suggest that the study of sport management requires a wider social and ethical dimension to its analyses. In attempting to develop critical research into sport management we ask how can the social theory of Pierre Bourdieu assist sport management research? This paper explicates the benefits of Bourdieu to sport management by suggesting a dynamic, relational approach to the implementation of his practice theory. We introduce the foundations of his opus and review their previous application in the study of organized sport. Drawing on these concepts we recommend adopting a longitudinal, critical, and ethnographic approach for a more nuanced understanding of how complex phenomena impact on the management of sport. This paper presents conceptual and methodological implications in conjunction with a call for further research to increase our critical understanding of sport management.

(c) 2012 Sport Management Association of Australia and New Zealand. Published by Elsevier Ltd. All rights reserved.
\end{abstract}

\section{Introduction}

Currently there are some key issues that highlight the negative underbelly of sport and of those who manage it. For instance, the threat, and practice of corruption is an issue that involves many stakeholders across the business of sport as highlighted in the work of Jennings (2011) and Mason, Thibault, and Misener (2006). Likewise both Anderson (2009) and Cunningham (2008) recently claimed that gender inequality is a practice which is institutionalized into organized sport's fabric. It is the challenge for research to enlighten practitioners to work toward practices that overcome these and other problematic practices so that positive change can be achieved. Whether sport management has used the theoretical and methodological tools within its possession to fully comprehend the ramifications of these issues is debatable.

Love and Andrew (2012) recently suggested that cross-fertilization between the sociology of sport and sport management could potentially achieve greater benefits for both fields. While this call is important it is not new. Indeed it was first outlined by Slack and Kikulis (1989) in their critique of how organization theory had been ignored by sport management. Although organization theory's benefits to the study of sport management was addressed in the multitude of studies that followed (Amis, Slack, \& Hinings, 2002; Kikulis, Slack, \& Hinings, 1992, Kikulis, Slack, \& Hinings, 1995a, Kikulis, Slack, \& Hinings, 1995b; Slack \& Hinings, 1992, 1994) recently theorists have called for more critical approaches to the study

\footnotetext{
* Corresponding author. Tel.: +44 02890368213.

E-mail addresses: pj.kitchin@ulster.ac.uk (P.J. Kitchin), P.D.Howe@lboro.ac.uk (P. David Howe).

${ }^{1}$ Tel.: +440150922 6389.
} 
of sport management (Amis \& Silk, 2005; Frisby, 2005; Skinner \& Edwards, 2005). These scholars suggest a deeper engagement with social and critical theory to provide a more robust framework to investigate complex phenomena, such as corruption, the marginalization of minority groups, how inequalities are reproduced with sport, and how organizations change in light of these issues. In this paper we seek to build upon these calls for greater critical engagement by proposing a relational deployment of Pierre Bourdieu's practice theory that potentially could benefit sport management research.

This paper has a dual purpose. First, it will examine the nascent use of Bourdieu in sport management research and show how those in the field have engaged with his various concepts. Second, we will argue that a relational approach drawing on his 'master concepts' (Swartz, 2008) of field, capital, and habitus provide a multi-layered analysis that positions sport management within its wider social and institutional context, while also acknowledging its micro-level realities. Our question is; how can the social theory of Pierre Bourdieu assist sport management research? In order to answer this question we aim to demonstrate how this relational approach can lead to a critical, yet multi-layered analysis of sport management, which would permit the conceptualisation of complex phenomena such as corruption, inequality, or marginalization. In order to achieve this we have divided the paper into the five parts following this introduction. As Bourdieu's coverage in sport management journals is sparse we will first introduce readers to his work and illuminate his key concepts through an analogous example. Despite the general lack of adoption in sport management Bourdieu's concepts have been used by a number of researchers investigating organized sporting practice. The second part will review these studies to provide an overview of the foundations of our current level of knowledge. In our discussion we present an example of where relational analysis was effectively applied and how it demonstrates a more holistic and complex explanation of sport management phenomena. We follow this discussion with a section addressing the conceptual and methodological implications for sport management researchers. Finally, the conclusion provides a summary of these proposed benefits and presents areas for possible further research.

\section{Introducing Bourdieu's Practice theory}

Bourdieu's version of practice theory can be used by researchers as a toolkit to help provide social explanations of everyday life. The most frequently used concepts in the organization and management literature are those of field, capital, and habitus (Emirbayer \& Johnson, 2008). Although discussed in greater detail below they are briefly outlined here. Field can be defined as a structured and objective network of social relations where agents are engaged in a contest for resources and position. Capital was used by Bourdieu to explain certain 'tools' used by agents to contest these resources and field positions. Habitus is defined as a set of continually refined dispositions, appreciations and perceptions that provide agents with meaning within field specific circumstances.

Although these terms have been often used in research related to organized sport we argue it is the relational implementation of these concepts that can offer greater explanatory power. In order to demonstrate the relationships between field, capital and habitus we use analogy of a professional sport league. By using this analogy we hope to demonstrate the relationships between the concepts and how changes in one concept impact on the other two. This relational approach implies two considerations. First, an ontology must be adopted that considers the wider context of sport management than one limited to its organizational boundaries. The management of sport must be viewed in its wider social and ethical environments (Skinner \& Edwards, 2005). Second, a relational approach should seek to build theory. For instance, despite a body of work exploring organizational change in sport (Cunningham, 2002; Slack \& Hinings, 1992; Stevens \& Slack, 1998), more theories explaining the interaction between the macro and micro forces at work in this process are required.

In order to address these two considerations time is an important variable to consider. Time permits organizational and institutional developments to be observed in relation to their wider social context. Presently there is an over-dependence on analysis of static, cross-sectional data from current managers embedded within organizations (Mutch, Delbridge, \& Ventresca, 2006). We seek to outline an option for how time can be included as a variable in its own right, in accounts of organizational life.

\subsection{Analogy: a professional sport league}

Central to practice theory is the relationship between each of its various concepts. While Bourdieu used an analogy of a game of cards to highlight the interdependence of these components (Bourdieu \& Wacquant, 1992) we use a generic example of a professional sport league. It does not represent any one league in particular but it does incorporate some elements of many professional leagues. The setting ( field) for the league is a social area that has its own rules and "regularities" (Bourdieu \& Wacquant, 1992). These regularities manage the relationships between the field's stakeholders (fans, players, coaches, teams, owners, governing bodies, media, and commercial sponsors). These relationships determine the structure of the league. For instance, the higher the media profile of the league the more significant the financial stakes of the commercial partners involved. Smaller leagues that are less attractive may have fewer stakeholders.

Through these relationships certain dispositions (ways of playing and operating within the league) are created and given value. An acceptance of these values is unconsciously agreed by all stakeholders within the league in order to give the game its meaning. To come to an understanding of what is valued one must learn to accept these values by participating in the league. Through this participation agents adopt certain practices and strategies that allow them to increase their understanding of the league (practical sense) and simultaneously create field-specific dispositions (habitus) toward the game. 
Table 1

The master concepts of Bourdieu's Practice theory.

\begin{tabular}{ll}
\hline Term & Definition \\
\hline Field & $\begin{array}{l}\text { Networks of social relations, structured systems of social positions within which struggles or manoeuvres take place over resources, } \\
\text { stakes and access. (Bourdieu, 1990) (see Section 3.1) }\end{array}$ \\
Capital & $\begin{array}{l}\text { "Capital is accumulated labor (in its materialized form or its 'incorporated' form) which, when appropriated on a private... basis by } \\
\text { agents... enables them to appropriate social energy in the form of reified or living labor." (Bourdieu, 1986, p. 241) (see Section 3.2) } \\
\text { Habitus }\end{array} \quad \begin{array}{l}\text { An open system of dispositions, appreciations and perceptions that provides meaning. These meanings are constantly subjected to } \\
\text { experiences and therefore go through an ongoing process of refinement. (Bourdieu \& Wacquant, 1992) (see Section 3.3) }\end{array}$ \\
\hline
\end{tabular}

This practical sense is cultivated and honed through repeated exposure to the league's operating conditions (practice). Stakeholders learn to pre-recognise game conditions allowing them to use their experience to read the present and to also predict future possibilities (Bourdieu \& Wacquant, 1992). While these possibilities are influenced by their previous history in the league it does not mean that stakeholders definitely follow these experiences, as many new choices and paths are possible.

Participation in the league allows agents to earn and accumulate stakes. These stakes are the products of competition between stakeholders called capital. Capital is specific to the league and can be used as a tool by agents to implement a variety of strategies. The specific volume and constitution of capital an agent possesses determines the power and utility of these tools. An agent with many tools can implement more strategies than those that do not have compatible tools, which result in adopting positions of dominance in the field. The possession of capital allows agents to adopt a certain stance (position) in the hierarchy of the league (field). Both an individual fan and an official broadcaster are positioned in the field. Given that they generally would differ in their levels of capital resources they exist in different positions in the field. Hence the possession of these tools determines an agent's status and position within the league. Movement within the field is determined by three factors; a stakeholder's "force in the game", their current "position", and their "strategic orientation toward the game" (Bourdieu \& Wacquant, 1992). By force in the game we imply the relationship between their disposition and their capital. Moving up the hierarchy of field positions (position-taking) allows an agent to adopt new strategies. Hence while many individual fans may lack the capital resource of a broadcaster it is possible for fans to collectivize in order to elevate their field position.

This analogy has attempted to demonstrate the relationship between habitus, field, and capital. We used this approach to introduce the terms and show how they relate in a league setting. Essentially, this relational approach suggests that changes in the field, such as an increase in professionalization of the sport league, will have consequences for the capital and habitus used to position agents. In turn, a shift in the capital and/or habitus will impact on the field (Table 1).

\section{Bourdieu's use in previous organized sport research}

This section will review how the literature on the management of organized sport has engaged with Bourdieu's concepts. The purpose of this section is to examine each concept in greater detail before addressing some key issues with its implementation in the literature.

\subsection{Field}

A field is a social arena that provides the setting in which agents struggle for resources (Bourdieu, 1990; Washington \& Ventresca, 2008). Rather than being conceptualized as a boundary of economic activity, fields are complex networks of relationships. The field itself is an 'objective, structured system' of social positions. This objective, structured system means that fields such as professional sport possess an operating logic that is different from other fields of human activity, such as health, arts, or education. These logics differentiate the field as logic pre-determines an agents' perception of which stakes are valuable, and how one should attempt to acquire them.

Within the organization and management studies literature field is the most commonly used concept of Bourdieu's opus. Scholars from these areas have been influenced by DiMaggio and Powell's (1983) and Scott's (2005) institutional interpretations of the organizational field. DiMaggio and Powell (1991) define the organizational field as:

"those organizations that, in the aggregate, constitute a recognized area of institutional life: key suppliers, resource and produce consumers, regulatory agencies, and other organizations that produce similar services and products." (pp. 64-65)

This emergent term has been used to describe a collective of organizations involved in some form of industry. However, it is not only organizations that comprise a field, indeed individuals are also field agents. Bourdieu (2005) viewed fields as either restricted or unrestricted. A restricted, autonomous field (the field of restricted production) is isolated from wider social forces and operates on self-determined principles. This field is concerned with producing goods intended for other producers of cultural goods. A widespread, heteronomous field (the field of unrestricted production) produces goods for the public at large and is concerned more with colonizing autonomous fields in its attempt to create field heteronomy. Once a heteronomous field subjugates an autonomous field colonization occurs. Where this has not occurred a field can still be 
considered autonomous (Everett, 2002). For instance, the professional league used in the analogy may become oriented towards the commercial realities of sponsors and broadcasters in their quest to sell an entertainment product. This may conflict with the traditional sport-focused logic that developed with sport's evolution.

This concept has proved relatively popular with sport management scholars investigating change in organizational and institutional settings (Augestad, Bergsgard, \& Hansen, 2006; Cousens \& Slack, 2005; Enjorlas, 2002; Skille, 2011). The benefit of this theoretical device to institutional theorists is outlined by O'Brien and Slack (2003), who stated:

"All sport organizations are embedded in organizational fields, and are subject to pressures from key suppliers, resource and product consumers, competitors and regulatory agencies. This makes the organizational field level of analysis extremely apropos for analyses of organizational changes in sport." (p. 419, emphasis added)

Augestad et al. (2006) used this organizational field concept to examine change in elite Norwegian sport. They found that field-effects (similar changes between and within organizations) occurred as successful archetypes were adopted by Norwegian National Governing Bodies (NGB's) following their benchmarking of other successful sporting nations.

Studies which examine field-level change and conflict as a result of new entrants entering the field are increasing (Cousens \& Slack, 2005; O’Brien \& Slack, 2003; Washington \& Ventresca, 2008; Washington, 2004). Examining field as an objective setting without links to habitus or capital (in isolation) does not completely explain the role of power in the process of change. Broadcasters are an increasingly powerful stakeholder in professional sport leagues such as the league outlined in the analogy. If they can suggest alterations to the sport's schedule we can assume that their elevated field position, significant capital resources and disposition towards commercialization might strengthen their request. This power wielded could result in more games that suit the broadcasting schedule rather than the athletes. The importance of examining power is that it assists explanations of shifts to a field's logic, norms, and values over time (Washington \& Patterson, 2011). An organizational field's logic determines a number of factors, namely what is deemed acceptable and unacceptable behaviour, how means and ends relationships are justified, power relations of the social order, and how resources are distributed across an organizational field (Gammelsæter, 2010; Washington \& Patterson, 2011). Shifts in logic can lead to change and/or resistance from agents within the field they inhabit. The colonization of sport by the commercial field has shifted logics from traditional sport-focused narratives to those of entertainment. Once colonized by the new logic of the heteronomous field, a field's values reflect those of the dominant agents over the original values of the sport. Dominant agents can use their rich resources and elevated field position to reproduce activities that reinforce their values (Brown, 2008; Cousens \& Slack, 2005; O'Brien \& Slack, 2003). By way of example Brown (2008) highlighted the dilemma that faced Canadian Olympic athletes as the Olympic field was colonized by a corporate logic. No longer did athletes receive the same level of symbolic value for their work. The new logic gave primacy to the 'team' effort through total medal counts and final medal table positions. Indeed the corporate backers were more easily included in this team image reducing the profile of the many individual athletes who excelled.

It is clear that struggles for the right to determine the logic and power relations of organizational fields are part of institutional life (Washington \& Ventresca, 2008). However, when thinking relationally it is important to examine the impact of change in a wider context. Wright (2009) demonstrated that fields are relational and multi-layered. She examined the varying layers of field (individual, organizational and social) and their role in fostering institutional change within English cricket. She found that one of the major causes for change came not from within the sport's organizational field but from shifting perspectives on social life in the wider societal field that cricket existed within. In this case change occurred as individual players reconsidered their social positions in the wake of the Second World War. In light of this war British prewar social divisions were re-visited resulting in shifts in collective values away from those of liberal, 'Victorian-England' to an emerging communal, welfare state. This shift impacted within cricket, subsequently reducing the power of the dominant amateur athlete and increasing the power of previously dominated professional players.

An important contribution to this relational thinking was made by O'Brien and Slack(2003) who examined change within the organizational field of English Rugby Union during the onset of professionalism. They showed that the field dynamics of rugby changed when new entrants and their new capital entered. As new entrants entered the field changes to the valued capital (economic over cultural) ushered a resultant shift in the priorities within the sport. The authors demonstrated that this shift was relational; as the potential for profit from the sport was realized new entrants entered the domain in an attempt to extract these profits. As economic capital became more important, traditional values and modes of operating were transformed to conform to this commercial logic.

\subsection{Capital}

Bourdieu conceived two types of capital; economic (an agent's actual or potential finances) and cultural (an agent's embodied, objectified or institutionalized cultural resource; which can take the form of education level or expertise). In Bourdieu's work an agent's position in the field is determined by the types and volumes of capital they possess (Bourdieu, $1998,2005)$. This capital is a relational signifier of taste, hence the right mix of economic and cultural capital permits agents to differentiate themselves from others. Capital is also an embodied resource. Over time it is accumulated through practice. In the analogy athletes develop their physical capital to suit game conditions. Athletes practice their skills in order to develop more robust forms of capital. However, if athleticism replaces strength as games' dominant capital players must either retrain to acquire the skill or exit the game. Subtle variations in capital exist when applying capital in an organizational 
sense. Economic and cultural capital are expanded to include other forms of capital, such as technological (a portfolio of scientific resources), juridical (legal regulations), and commercial (sales power) capital. ${ }^{2}$ This expanded set of capital forms the strategies used by organizations in seeking and sustaining competitive advantage. While Bourdieu is renowned for his work on capital (Bourdieu, 1984) he is not the only theorist who has used the term, nor is he the only one that sport scholars draw upon.

Since 2000 social capital has become of increasing importance to the study of sport management, featuring in over forty articles across the four main sport management journals (Shilbury, 2011). An influx of social capital narratives has increased in tandem with the encroaching neoliberal agenda for sport and this agenda's acceptance that sport and leisure builds social capital (Putnam, 2000; Skinner, Zakus, \& Cowell, 2008). Neo-liberal ideals have proven very difficult to argue against (du Gay, 2000) and increasingly difficult to quantitatively or qualitatively measure. Skinner et al. (2008) argued that sport organizations in Australia should increase their efforts to develop social capital as a means of justifying their ongoing community significance. While the researchers drew on evidence that sport contributed to the development of social capital Crabbe (2007) suggests that many studies overstated a "conventional functionalist interpretation" (p. 39) that leads to the assumption that sport does good for people who play it, and therefore this leads to the development of social capital. The works of Coleman (1988) and Putnam $(1993,2000)$ on social capital have been used extensively across many academic areas (Hughes \& Blaxter, 2007). In order to provide some detail on these perspectives on social capital we will briefly introduce the various theorists and their use in the literature. In this paper we draw on Bourdieu's (1986) definition of social capital as:

"the sum of the resources, actual or virtual, that accrue to an individual or a group by virtue of possessing a durable network of more or less institutionalized relationships of mutual acquaintance and recognition." (p. 251)

Coleman (1988) developed his version of social capital by examining how family units develop trust. According to Coleman's theory social capital is formed through an instrumental and functional process. Over time, parents consciously ensure that their offspring have access and opportunities. These actions build trust within the family network. Bourdieu's approach to social capital also follows this instrumental thesis by viewing social capital as a resource that can be gathered by increasing one's networks. He argued that social capital accumulation is constrained as it is dependent on the other types and volumes of capital an agent may possess (Sempel, 2005, 2006; Spaaij, 2009). Hence if individuals lack economic and/or cultural capital they will not be able to enhance their social capital. In this respect Bourdieu saw social capital as a limited resource; one in which there was only so much to go around. Underpinning both Coleman and Bourdieu's perspectives is the notion of investment by individuals in their capital over time.

By contrast Putnam's (1993) notion of social capital is more communitarian. His examination of the social structures in the north and south of Italy led him to conclude that the greater the number of horizontal networks between civic groups the more prosperous the community. Putnam (2000) extended his theory on social capital in an examination of civic bonds in North America and argued that opportunities for social capital development were in decline. While Coleman viewed social capital operating at an individual, micro level Putnam's perspective on social capital had its roots in the civic arena, operating at meso and macro levels.

Through his work Putnam outlined two types of social capital. The first is bonding social capital, which is defined by Tonts (2005) as:

"[the development] of trust and reciprocity within dense or closed networks. It tends to be inward looking and reinforces exclusive identities and homogenous groups (e.g. the bonds within a closely knit sporting club)." (p. 138)

Tonts (2005) suggested that while some positive impacts were acknowledged through bonding social capital, the closed nature of these networks created barriers that excluded others. Adams (2012) termed bonding social capital as 'defensive social capital', one in which social closure (Coleman, 1988) occurred. Individuals who are outside this closed network find their chances of community involvement limited. This means that although sport can be shown to build social capital it can also act to further marginalize certain populations. Bourdieu viewed marginalization as a likely outcome for any individual who did not possess the requisite levels of economic or cultural capital. A common criticism of Bourdieu is that while economic and cultural capital may well exclude individuals his conceptual framework makes no mention of race or gender (Hughes \& Blaxter, 2007; Jenkins, 2002), which Tonts (2005) highlighted as marginalizing factors. Within organized sport individuals and organizations with greater access to cultural or economic capital enjoyed greater proclivity for accumulating social capital (Sharpe, 2006). Hence, capital that creates links between diverse communities and provides a more robust method of developing community networks is required. To highlight the potential of community network development Tonts' (2005) used Putnam's bridging social capital, which:

"refers to wider overlapping networks that generate broader identities and reciprocity (e.g. links between people from other social groups which may differ in religion, ethnicity, or socio-economic status)." (p. 138)

Maxwell and Taylor (2010) found that bridging social capital occurred within community sports when team partners and sponsors provided opportunities for club members to participate in community activities. Both bonding and bridging social

\footnotetext{
${ }^{2}$ An additional form of capital, human capital has also been examined by sport management researchers (Barros \& Barros, 2005) however, Bourdieu viewed human capital as subsumed within cultural capital (Lin, 2001).
} 
capital emphasize horizontal linkages within and between community groups. However, opportunities for vertical development remained scarce.

To address this Woolcock (2001) developed a third, vertical form of social capital. This version suggests that vertical networks which develop between groups will lead to greater reciprocity and mutuality for marginalized groups. These vertical networks therefore permit groups to form relationships with those possessing greater levels of power. Sherry (2010) comments that linking social capital is one that:

"delineates those relationships between individual and groups that cross boundaries, drawn from dissimilar situations. It is linking capital which allows members to leverage a much wider range of resources than those within their own community." (p. 62)

Research on 'Homeless Sport' has revealed how individuals from marginalized groups can build networks and contacts through linking social capital from participation in sport (Sherry, 2010). Individuals who suffered hardship and homelessness established contacts with organizations involved with the competition, thus building vertical links in addition to other bonding and bridging links. While from a sports policy perspective each of these types of social capital is important, these previous studies have stressed the importance of designing activities to favour bridging and linking capital so that the limitations of bonding capital are overcome.

Hoye and Nicholson (2011) examined social capital development in regional horse racing communities. Respondents drawn from the upper echelons of community racing organizations and other community groups reported that horse racing activities contributed to community social capital. However, we believe there were some missed opportunities in Hoye and Nicholson's (2011) approach. Firstly, the data relied on interviews from leaders and managers who critically speaking might have an interest in overstating the community benefit they feel horse racing offered. Second, by focusing on the opinions of managers there was little way of demonstrating that the clubs are indeed as inclusive as they claim. If social capital can be developed through these organizations, what occurs to those who do not interact with their services? If a community benefit implies one that benefits all of the community it is difficult to imagine this occurring in a gambling-led sport. Critically in the context of horse racing, what were the viewpoints of those who either won or lost gambling at the races? How could their social capital be enhanced by this involvement? While this study contributes to our understanding of the possible mechanisms of how social capital develops communities, particularly in rural areas, perspectives gained from outside the upper-echelons of community organizations could have strengthened these claims.

Using theorists such as Putnam and Woolcock is not problematic per se but we agree with issues raised by Sempel (2006) and Spaaij (2009) that by isolating any type of social capital it limits its explanatory power. Social capital can be placed into a relational analysis with other forms of capital to develop a greater critical awareness of its impact in sport. Bourdieu's social capital has been examined as a relational construct, in relation to field and also to other forms of capital. Sempel (2005, 2006) showed how sport existed in a relational structure in which certain sports are populated by individuals with certain levels of cultural capital. The space between these sports practices was labelled 'cultural distance'. For individuals and organizations to cross this cultural distance certain types and volumes of capital are required, which is not always assured (Sharpe, 2006). Spaaij (2009) also examined the interplay between economic, social and cultural capitals in sport. He found that previous studies had divorced social capital from other types of capital. As a result of this opportunities to demonstrate how sport developed economic and cultural capital were lacking. Despite finding that social capital development in rural northwestVictorian, Australian communities did occur, it was currently constrained to bonding and bridging types of capital only. Our point of departure with this and previous studies is that our proposed multilayered, relational analysis positions capital at the micro level (where Coleman and Bourdieu both held it) while we use habitus to provide us with meso-level analysis. By focusing on multiple levels we envisage that a wider array of perspectives can be conceptualized.

\subsection{Habitus}

Habitus is the central concept of Bourdieu's attempt to overcome the binary distinction between structure and agency. He did this by reconsidering the relationship between agents and their social worlds (Bourdieu \& Wacquant, 1992). Habitus is an unconscious process where wider culture is imbibed and embodied in individuals, and as a result informs their actions. In discussing habitus' application to individuals Howe (2007) stated that is "is the embodied sentiment of every encounter they have had in the social world" (p. 137). Despite receiving guidance from the objective, structured systems of the field habitus does not direct human action. Essentially habitus acts as another structured system, one that is unconscious and subjective, and which permits various modes of agency. Bourdieu (1977) explained habitus' interaction between its subjective structured system and the field's objective structured system, as:

"Habitus, inculcated by objective conditions engender aspirations and practices objectively compatible with those objective requirements, the most improbable practices are excluded." (p. 77)

Referring back to the analogy a business manager of the professional league who has risen through the ranks of the sport would have a strong grasp of how business is done within the league. These dispositions could, however, close off new ideas for developing the league as her/his aspirations are influenced by their previous work experiences.

Jenkins (2002) deemed contradictory that we can exhibit agency and not be ruled by the objective structure of the field. However, habitus works by structuring our preferences for our choices for social practice. Hence, we are still able to 
determine our own course of action. Nevertheless, the more deeply immersed agents are within a pronounced and well-articulated field, the greater the likelihood they will wish to maintain and replicate the field's structures by making choices that are deemed compatible with both the field and their habitus. When this does not occur tension can result. Some respondents in Taylor and Garratt's (2010) examination on the professionalization of coaching in the UK felt the emerging diktats from governing bodies did not suit the practice of sport at the grassroots level. This incompatibility between existing individual habitus and the new, emergent professional field logic led to tension between agents in a number of sports.

The dispositions that compose the habitus are shared amongst individuals regardless of their class, gender, ethnicity, and ability. Habitus produces rules and regularities that are reciprocally constructed in the field. These dispositions, like field logic, also state what is and what is not considered acceptable. While previous studies have examined the embodiment of habitus at an individual, micro level we need to understand how this is applicable to the management of sport. At the current time few examinations of meso-level habitus have been made (for exceptions see; Howe, 2007; Kay \& Laberge, 2002a; Stewart, Adair, \& Smith, 2011; Taylor \& Garratt, 2010); hence, further study is required. It is also important not to conflate organizational habitus with organizational culture. While the latter has examined the composition of organizational identities through analyses of symbols, memories, stories, and structures we argue that a relational use of organizational habitus provides a better understanding of how power works on the cultural identity of organizations. Organizational habitus focuses on the informal, unconscious practices which interact to guide the dispositions of the organization as a whole. Tatli (2010) defined organizational habitus as a process which "works as a historically constructed and informal logic, which governs the allocation of power positions in the organizational context" (p. 12). Like culture, organizational habitus can both direct and constrain action over time; hence, change is possible if the proposed change suits either the organizational culture or habitus. However, organizational habitus differs from culture in that it is constantly in flux. Tatli (2010) identified it as "a hybrid of organizational memory, i.e. the pre-established logic of the organizational culture, and multiple micro habitus, which are bought into the organization by organizational members” (p. 12). This hybrid posits a contested terrain where groups within the organization contest for "hegemony over the terms of organizational culture and power. Thus power relations are infused into the organizational habitus" (Tatli, 2010, p. 13). It is this failure to link organizational culture to wider social practices that makes organizational habitus a stronger, if under-utilized tool for understanding the internal organizational environment (McDonough, 1997). As yet no studies in sport management have drawn upon the above definition. Some examinations of habitus have taken place that have revealed how it can provide a strong expose of power in organizational analysis; however, as per the organization and management literature habitus has received the least attention of the three master concepts (Emirbayer \& Johnson, 2008).

Organizational habitus is a contested terrain. In his study on the integration of Paralympic athletes into Athletics Canada Howe (2007) drew attention to the tensions evident in the mixing of different micro habitus within the organizational space. The implementation of this policy of integration was impeded by the failure of the governing body to conceive the ramifications of incorporating the Paralympic habitus into an 'able-bodied' organization. Paralympic habitus in Canada was founded on a history of charitable development and like many Paralympic sports it possessed a complex classification system. The incompatibility of the existing elite-sport habitus of Athletics Canada and the emergent Paralympic athletic habitus resulted in the former dominating the latter, relegating it to a secondary position and thus weakening the process of integration.

Organizational habitus is also field-specific. As stated previously, the volume and type of capital an agent (organization or individual) possesses determines its position in the field. However, when a dominant agent in one field enters another field they may lack field-specific capital to maintain an equitable field position. A recent study by Stewart et al. (2011) demonstrated how organizational habitus is also field-specific. In their examination of illicit-drug-regulation policy in Australian professional sport they showed that despite medical and health professionals high status in their own medical field they did not possess an organizationally specific habitus for the field of professional sport. Hence, a dominant coalition of government and sport governing bodies was able to ensure the implementation of ideological policies that contrasted with the evidence-base of the professionals. The lack of field-relevant dispositions to the rules and regularities of the professional sport field meant that these medical and health professionals were marginalized from debates where they were experts.

Finally when field colonization does occur the logic of the field is transformed and the dominant organizational habitus follows suit. Howe (2008) examined the production of media narratives surrounding the Paralympic Games. These narratives focused themes such as 'overcoming adversity' and the 'triumph of the human spirit.' Each of these themes was given precedence by the International Paralympic Committee (IPC) in its media narratives. These themes were given primacy over the more accurate narratives that focused on tough, uncompromising competitors, and even issues concerning doping. As these narratives conflicted with the IPC's view on what its mediated publics preferred they were suppressed. Interestingly many of these preferred publics were not part of the disability community but rather the general viewing public. Ultimately the IPC revealed that its organizational habitus was more closely aligned with their global media partners (and their consumers) than with the communities from whence the IPC came.

From the above studies it is clear that mismatches between organizational habitus can result in conflict or lead to the marginalization of dominated agents at the behest of the dominant. Nonetheless despite organizational habitus being a useful concept in its own right when linked to field and capital it provides an important meso link with these layers of analysis. 


\section{Discussion}

The section above addresses our first purpose of this paper: to examine the nascent use of Bourdieu's practice theory in sport management research and show how his various concepts have been used. The following discussion will address our second purpose: to argue that a relational approach drawing on field, capital, and habitus can provide a multi-layered analysis that positions sport management within its wider social and institutional context, while also aiding in understanding its micro-level phenomena. To achieve this purpose we need to demonstrate how these master concepts work in a relational sense. We feel that explaining this process is essential if we wish to explicate its value to sport management research. Work by Sempel (2005) and Spaaij (2009) highlighted above show us that social capital can be better understood when positioned in the context of other types of capital. These authors view capital as a relational concept; when compared to other phenomena they become more readily understood. Our only point of departure from their studies is to apply this relational approach vertically between field, habitus, and capital. While the professional league analogy presented above served to introduce the master concepts it also intended to demonstrate the interconnectedness of Bourdieu's opus. To further demonstrate the benefits of relational analysis we draw on the work of Kay and Laberge (2002a,b) which represents two of the few studies that demonstrate a vertical, relational link. These studies encapsulate how Bourdieu can be used to analyze organized sport and demonstrate how a relational use of his master concepts can aide our understanding of multilevel forces at work in organizational change, or even across broader issues involving corruption, inequality, and marginalization. To premise this example few in sport management would argue against the fact that increasing participation is a common goal shared by many, if not all sports organizations. However, the functional benefit of increasing participants can affect the organization in different ways than originally conceived. Kay and Laberge (2002a,b) noticed that a shift in the collective habitus of the sport was the result of macro, meso, and micro level changes. We intend to use Kay and Laberge's (2002a,b) example to highlight the logic of our argument.

Change in the sport of adventure racing was a multi-faceted process (Kay \& Laberge, 2002a,b). First the ever-increasing corporatization/commercialization of the macro environment positioned the sport as a site rich for certain types of capital acquisition. Traditional participants held values that represented the original logic of the sport. These traditional participants occupied an elevated field position. The cultural capital sought by these participants was awarded through the successful maintenance of peak performance. Over time these participants were crowded out by an influx of new corporate participants whose values reflected an emergent, corporate logic. Due to the economic capital that these new participants brought to the sport they rapidly adopted an elevated field position. Instead of success being defined by peak performance these new entrants gained capital through participation alone. Participation in adventure racing provided corporate participants with an opportunity to use capital gained in racing as a symbol which was valued in their corporate field. Nonetheless it was not just exogenous pressures that facilitated these changes. Kay and Laberge (2002a,b) have demonstrated that at the micro level the sport's governing body implemented strategies to make the sport more appealing to both these new participants and also broadcast and commercial partners. These macro- and micro-level shifts effectively necessitated the changing habitus. This altered habitus within the sport was an outcome of increased corporate participation and yet contributed to the marginalization of the sport's traditional participants. In summary, Kay and Laberge's (2002a,b) work demonstrated how levels of analysis are interrelated and can provide a more holistic approach to understanding change in sport.

This section has outlined how the second purpose of this paper has been addressed. It has demonstrated a relational analysis of change in sport. Central to this example is an understanding that changes in one area of the organization impact on others and that the use of power by field agents can marginalize even the most traditional follower.

\section{Conceptual and methodological implications}

With the purposes of this review achieved the next step is to consider how we can use this theory to benefit sport management. At the beginning of this paper we posed the question; how can the social theory of Pierre Bourdieu assist sport management research? Theoretically speaking the answer may seem apparent from the above examples, which demonstrate the utility of the master concepts in organizational analysis. We have adapted Tatli's (2010) conceptual framework (see Table 2) in order to elucidate the key concepts and show how they relate to each level of analysis. At the macro level field can be determined by a number of components operating in the distal environment, such as PESTEL analysis. Components that comprise the macro level may occur also in the proximal environment, such as sport policy analysis, and the policies of sports councils and governing bodies. Mapping the field through these tools can provide an important snapshot of the conditions that sport organizations operate within. At the meso level the informal, contested nature of stories, symbols, values and other organizational phenomena comprise the organizational habitus. How this organizational habitus fits with the objective conditions of the field is an interesting area of analysis, particularly when organizations are performing above, or below industry expectations. Finally, at the micro level managerial strategies that seek capital accumulation are of interest. The volume and types of capital possessed by organizations and the strategies that managers use to increase their capital are of interest to analysis. Indeed strategies to acquire new capital result in positiontaking within the field and thus alter the relations between agents. It is our hope that future research could draw on all, or parts of this framework to conduct a relational analysis of sport management phenomena.

We argue that a more pressing concern is a greater awareness of the importance of methodology. Bourdieu's practice theory was more than a collection of theoretical concepts; it was a conjoined conceptual and methodological approach that 
Table 2

A relational model of Bourdieu's practice theory (adapted from Tatli, 2010).

\begin{tabular}{lll}
\hline Level of analysis & Practice theory concept & Additional components \\
\hline Macro & Field & $\begin{array}{l}\text { Distal: political and legal, economic, socio-cultural, technological, ecological } \\
\text { Proximal: government sport-related policy governing body policies, institutional structures and } \\
\text { practices } \\
\text { Meso }\end{array}$ \\
Micro & Organizational habitus & $\begin{array}{l}\text { Organizational stories, symbols, routines and rituals, control systems, structures, power structure, } \\
\text { values, interests } \\
\text { Types and volumes of capital possessed. Managerial strategies for capital (social, economic, cultural } \\
\text { and symbolic) accumulation. Rationales for seeking new capital }\end{array}$ \\
\hline
\end{tabular}

was tested and refined over a 40-year period. One of the fundamental challenges for sport management is to use critical research methods to build upon the knowledge gained from previous interpretive research designs. To adopt a critical perspective is not to suggest that all studies that have gone before have been uncritical but it does promote the transformative potential of research (Cooper, Ezzamel, \& Willmott, 2008) and is better suited to assist in the development of organizations (Skinner \& Edwards, 2005). Interpretive studies have contributed significantly to our shared knowledge base and are well suited to extend the scale and scope of our theoretical claims. However, by relying overly on analytical approaches that at times merely reinterpret phenomena offered from potentially dominant viewpoints suggests that we are missing wider perspectives. The repeated use of interviews and document analyses re-creates knowledge production into a 'quasi-quantitative' process. Some have even recommended longer engagement with the unit of analysis so mechanisms of change can be witnessed over time (Amis et al., 2002; Kikulis, 2000). Further use of practice theory is needed to inform the research context, to create the categories for organizing data and also to act as a lens for analysing the data from a critical and relational viewpoint.

In light of the above point we base our methodological considerations upon methods that have proven successful in the past. The first option is to follow a historical-narrative case approach which analyses historical documents, archives and other organizational documents (Washington \& Ventresca, 2008; Washington, 2004; Wright, 2009). The strength of Washington's and Wright's methodological approach is that it permits a relational understanding of field agents by examining change over time. The data collected through these approaches can be categorized $a$ priori into themes and then critically examined in light of practice theory. The second option is to adopt Bourdieu's reflexive sociology which uses ethnography as a key methodological tool (Bourdieu \& Wacquant, 1992; Howe, 2008; Skinner \& Edwards, 2005).

Researching organizational phenomena through an ethnographic approach can combine the formal data collection methods of document review, interviews and surveys with participant observation. Participant observation has been used effectively in the management of sport (Caza, 2000; Silk \& Amis, 2000; Skinner, Stewart, \& Edwards, 1999; Spaaij, 2012); however, further studies are required. Participant observation is essential for understanding the informal and unconscious dispositions that form the organizational habitus. A major drawback of this approach is the time, funding and support required to engage in field work. However, a solution exists that weds the need to apply and test theoretical perspectives to practical situations. Misener and Doherty (2009) rekindled Adler and Adler's (1987) active-member role for use in community sport management. This approach is a variation of participant observation, but instead of participating in all activities it permits the skills and experience of the researcher to benefit the organization. In essence, this approach may be more attractive to sport organizations as they can utilize an academic's skills in return for access. This method may be superior to participant observation as it allows the researcher "a more central position" (Adler \& Adler, 1987, p. 50) plus it facilitates the ability to participate and co-construct knowledge within the organization (Frisby, 2005; Misener \& Doherty, 2009). Another benefit is that it develops trust between the researcher and the organization, which can be crucial if seeking to facilitate transformative change. However, a possible limitation of adopting the active-member role in the sport management environment is that the process is easier when the situation under examination is observable. When management is in action at board or departmental meetings or in the delivery of programming activities it is readily observable due to the verbal nature of discussions. However, when work takes place beyond the view of the active member researcher, either at the desk or home it is more challenging to observe. In spite of this limitation the use of observations, interviews and document analysis within an ethnographic approach can help to pick apart some of the more nuanced aspects of the organization (Skinner \& Edwards, 2005). Indeed Bourdieu's (1990) use of habitus is well-suited to organizational and institutional settings as he claims:

"it [is] possible to inhabit institutions, to draw on them practically, enacting their organizing principles and thus reproducing them but at the same time allowing for revisions and transformation" (p. 57).

From the sections above we have clearly achieved our purpose. We have also addressed our question and can emphatically answer - yes - Bourdieu offers potential for sport management research but it should be adopted as the theorist himself intended, through a conjoined conceptual and methodological approach. Hence, if practice theory and reflexive sociology, particularly using ethnography can lead to an expose of the conditions which lead to inequality or the marginalization of agents in the sport field then it could be a useful device for academics to support managers in sport to bring about change. 


\section{Conclusion}

From the above review a number of points are pertinent. First, over the past decade aspects of Bourdieu's practice theory have been used effectively by researchers investigating the social aspects of sport. Crucially the relational use of Bourdieu's tools has revealed subtleties about the role of power in organizational settings. Second, while a few sport management researchers have sought to examine aspects of Bourdieu's opus, many have not used these tools in this full, relational sense. While sound contributions have been made to the literature, particularly in the areas of organizational field and social capital more remains to be done. Third, our understanding of organizational habitus in sport management is under-developed and will require more examination by drawing on suitable methods. Finally, sport management scholars engaged in research on organizational and institutional change have attempted to combine theoretical perspectives to provide greater understanding of institutional phenomena (Cunningham, 2002; Slack \& Hinings, 1992; Stevens \& Slack, 1998). While this is of merit we envisage an alternative approach.

Bourdieu's practice theory can offer a multi-dimensional and relational analysis of the interplay between field, capital, and habitus. Significantly it can reveal aspects of power within the management of sport through an examination of the reproduction of inequality. In doing so it can explain unconscious actions that can inadvertently marginalize groups, or reveal how dominant agents wield strategies to maintain inequality. We believe there are some research areas that could benefit from a Bourdieuian, relational analysis. Empirical data are required to further enhance our understanding of how dominant stakeholders in sport are able to reproduce certain values while maintaining the perceived status quo over the beneficiaries of public investment in sport. Modernization is an institutional pressure in the form of the neoliberal colonization of restricted fields, such as sport. Academics have been seeking to gain a greater understanding about the interplay between micro and macro pressures within the organizational field. Arguments concerning the priorities outlined in Crawford's (2009) investigation into the public funding of Australian sport provide an interesting context for the [re]production of institutional values of sport's dominant stakeholders. Further study could examine capital and field strategies that the dominant employ to maintain their powerful positions. Studies could seek to examine cases concerning chronically underfunded organizations such as those involved in the management of disability sport - who could also benefit from an active-member approach - and their attempts to gain legitimacy from policy makers while also serving their members. Finally the arena of sport-for-development and peace has witnessed rapid growth of non-governmental agencies delivering sport in many international contexts. While some have asked questions of the logic guiding these sporting practices (Coalter, 2010; Darnell, 2012; Guest, 2009) they represent a burgeoning field of study. Longitudinal field studies drawing on practice theory could serve the monitoring and evaluation of these initiatives.

A relational use of Bourdieu's practice theory poses a number of potential benefits for sport management. First, a relational approach using Bourdieu's practice theory provides a theoretically substantive model for examining a range of sport management phenomena, particularly when an analysis of an organization's wider context is paramount. Second, it provides a link between macro and micro analysis through the deployment of the meso-level concept of organizational habitus. This concept permits an analysis of the contested nature of organizations and how power is used to interpret macrolevel forces in order to implement micro-level strategies. We believe that as yet, sport management has not drawn on the full potential of Pierre Bourdieu. However, the opportunities presented above could redress this imbalance and develop a more critical understanding of sport management.

\section{Acknowledgements}

The authors would like to express their sincere gratitude for the detailed insights provided by the Reviews Editor and the anonymous reviewers.

\section{References}

Adams, A. (2012). Big society-big deal: Gauging the threat to the social capital of sport in England. Paper presented at the International Sociology of Sport Association conference, Glasgow Caledonian University, 17th July.

Adler, P. A., \& Adler, P. (1987). Membership roles in field research. Beverly Hills, CA: Sage.

Anderson, E. D. (2009). The maintenance of masculinity among stakeholders of sport. Sport Management Review, 12, 3-14.

Amis, J., \& Silk, M. (2005). Rupture: Promoting critical and innovative approaches to the study of sport management. Journal of Sport Management, 19, 355-366.

Amis, J., Slack, T., \& Hinings, C. R. (2002). Values and organizational change. The Journal of Applied Behavioural Science, 38, $436-465$.

Augestad, P., Bergsgard, N. A., \& Hansen, A. O. (2006). The institutionalization of an elite sport organization in Norway: The Case of Olympiatoppen. Sociology of Sport Journal, 13, 293-313.

Barros, C. P., \& Barros, C. (2005). The role of human and social capital in the earnings of sports administrators: A case study of Madeira Island. European Sport Management Quarterly, 5, 47-62.

Bourdieu, P. (1977). Outline of a theory of practice. Cambridge: Polity Press.

Bourdieu, P. (1984). Distinction: A social critique of the judgment of taste. Cambridge. MA Harvard University Press.

Bourdieu, P. (1986). The forms of capital. In J. Richardson (Ed.), Handbook of theory and research for the sociology of education (pp. 241-258). New York, NY: Greenwood.

Bourdieu, P. (1990). The logic of practice. Cambridge: Polity Press.

Bourdieu, P. (1998). Practical reason. Cambridge: Polity Press.

Bourdieu, P. (2005). The social structures of the economy. Cambridge: Polity Press.

Bourdieu, P., \& Wacquant, L. J. D. (1992). An invitation to reflexive sociology. Cambridge: Polity Press. 
Brown, D. A. (2008). From the partners in pursuit of excellence to own the podium. An Ideological Slip in Canadian Olympic Sport. In R. K. Barney, M. K. Heine, K. B. Wamsley, \& G. H. MacDonald (Eds.), Pathway: Critiques and discourse in Olympic research: Ninth international symposium for Olympic Research (pp. 432-447). Beijing: Capital University of Beijing.

Caza, A. (2000). Context receptivity: Innovation in an amateur sport organization. Journal of Sport Management, 14, $227-242$.

Coalter, F. (2010). The politics of sport-for-development: Limited focus programmes and broad gauge problems? International Review for the Sociology of Sport, 45 , 295-314.

Coleman, J. S. (1988). Social capital in the creation of human capital. American Journal of Sociology, 94, S95-S120.

Cooper, D. J., Ezzamel, M., \& Willmott, H. (2008). Examining 'institutionalization': A critical theoretic perspective. In R. Greenwood, C. Oliver, K. Sahlin, \& R. Suddaby (Eds.), The Sage handbook of organizational institutionalism (pp. 673-701). London: Sage.

Cousens, L., \& Slack, T. (2005). Field-level change: The case of North American major league professional sport. Journal of Sport Management, 19, 13-42.

Crabbe, T. (2007). Reaching the 'hard to reach': Engagement, relationship building and social control in sport based social inclusion work. International Journal Sport Management and Marketing, 2, 27-40.

Crawford, D. (2009). The future of sport in Australia. http://www.sportpanel.org.au/internet/sportpanel/publishing.nsf/Content/crawford-report (accessed 25.11.11).

Cunningham, G. B. (2002). Removing the blinders: Toward an integrative model of organizational change in sport and physical activity. Quest, 54, 276-291.

Cunningham, G. B. (2008). Creating and sustaining gender diversity in sport organizations. Sex Roles, 58, 136-145.

Darnell, S. (2012). Sport for development and peace: A critical sociology. London: Bloomsbury Academic.

DiMaggio, P. J., \& Powell, W. W. (1983). The iron cage revisited: Institutional isomorphism and collective rationality. American Sociological Review, 48, 147-160.

DiMaggio, P. J., \& Powell, W. W. (1991). Introduction. In W. W. Powell \& P. J. DiMaggio (Eds.), The new institutionalism in organizational analysis (pp. 1-38). Chicago, IL: University of Chicago Press.

du Gay, P. (2000). Entrepreneurial governance and public management: The anti-bureaucrats. In J. Clarke, S. Gewirtz, \& E. McLaughlin (Eds.), New managerialism, new welfare (pp. 62-81). London: Sage.

Emirbayer, M., \& Johnson, V. (2008). Bourdieu and organizational analysis. Theory and Society, 37, 1-44.

Enjorlas, B. (2002). The commercialization of voluntary sport organizations in Norway. Nonprofit and Voluntary Sector Quarterly, 31, 352-376.

Everett, J. (2002). Organizational research and the praxeology of Pierre Bourdieu. Organizational Research Methods, 5, 56-80.

Frisby, W. (2005). The good, the bad, and the ugly: Critical sport management research. Journal of Sport Management, 19, 1-12.

Gammelsæter, H. (2010). Institutional pluralism and governance in commercialized sport. European Sport Management Quarterly, 10, 569-594.

Guest, A. M. (2009). The diffusion of development-through-sport: Analysing the history and practice of the Olympic Movement's grassroots outreach to Africa. Sport in Society, 12(10), 1336-1352.

Howe, P. D. (2007). Integration of Paralympic Athletes into athletics Canada. International Journal of Canadian Studies/Revue international d'etudes candiennes, 35 , $133-150$

Howe, P. D. (2008). The cultural politics of the paralympic movement. London: Routledge.

Hoye, R., \& Nicholson, M. (2011). Life at the track: Country race clubs and social capital. International Review for the Sociology of Sport, 46, 1-14.

Hughes, C., \& Blaxter, L. (2007). Feminist appropriations of Bourdieu: The case of social capital. In T. Lovell (Ed.), (Mis)recognition, social inequality and social justice (pp. 103-125). London: Routledge.

Jenkins, R. (2002). Pierre Bourdieu (2nd ed.). London: Routledge.

Jennings, A. (2011). Investigating corruption in corporate sport: The IOC and FIFA. International Review for the Sociology of Sport, 46, 387-398.

Kay, J., \& Laberge, S. (2002a). The 'new' corporate habitus in adventure racing. International Review for the Sociology of Sport, 37, 17-36.

Kay, J., \& Laberge, S. (2002b). Mapping the field of AR: Adventure racing and Bourdieu's concept of field. Sociology of Sport Journal, $19,25-46$.

Kikulis, L., Slack, T., \& Hinings, B. (1992). Institutionally specific design archetypes: A framework for understanding change in national sport organizations. International Review for the Sociology of Sport, 27, 343-370.

Kikulis, L. M., Slack, T., \& Hinings, B. (1995a). Does decision-making make a difference? Patterns of change within Canadian national sporting organizations. Journal of Sport Management, 9, 135-153.

Kikulis, L. M., Slack, T., \& Hinings, B. (1995b). Sector specific patterns of organisational design change. Journal of Management Studies, 32, 67-100.

Kikulis, L. M. (2000). Continuity and change in governance and decision making in national sport organizations: Institutional explanations. Journal of Sport Management, 14, 293-320.

Lin, N. (2001). Social capital: A theory of social structure and action. New York, NY: Cambridge University Press.

Love, A., \& Andrew, D. P. S. (2012). The intersection of sport management and sociology of sport research: A social network perspective. Sport Management Review, $15,244-256$.

Mason, D. S., Thibault, L., \& Misener, L. (2006). An agency theory perspective on corruption in sport: The case of the International Olympic Committee. Journal of Sport Management, 20, 52-73.

Maxwell, H., \& Taylor, T. (2010). A culture of trust: Engaging Muslim women in community sport organizations. European Sport Management Quarterly, 10, 465483.

McDonough, P. M. (1997). Choosing colleges: How social class and schools structure opportunity. New York, NY: State University of New York.

Misener, K., \& Doherty, A. J. (2009). A case study of organizational capacity in nonprofit community sport. Journal of Sport Management, 22(4), 457-482.

Mutch, A., Delbridge, R., \& Ventresca, M. (2006). Situating organizational action: The relational sociology of organizations. Organization, $13,607-625$.

Putnam, R. D. (1993). Making democracy work: Civic trends in modern Italy. Princeton: Princeton University Press.

Putnam, R. D. (2000). Bowling alone: The collapse and revival of American community. New York, NY: Simon \& Schuster.

O'Brien, D., \& Slack, T. (2003). An analysis of change in an organizational field: The professionalization of English rugby union. Journal of Sport Management, 17, $417-448$.

Scott, W. R. (2005). Institutions and organizations: Ideas and interests (3rd ed.). Los Angeles, CA: Sage.

Sempel, C. (2005). Adult participation sports as cultural capital: A test of Bourdieu's theory of the field of sport. International Review for the Sociology of Sport, 40 , $411-432$

Sempel, C. (2006). Gender, social class, and the sporting capital-economic capital nexus. Sociology of Sport Journal, 23, $273-292$.

Silk, M., \& Amis, J. (2000). Institutional pressures and the production of televised sport. Journal of Sport Management, 14, 267-292.

Sharpe, E. K. (2006). Resources at the grassroots of recreation: Organizational capacity and quality of experience in a community sport organization. Leisure Sciences, 28, 385-401.

Sherry, E. (2010). (Re)engaging marginalized groups through sport: The Homeless World Cup. International Review for the Sociology of Sport, 45, 59-71.

Shilbury, D. (2011). A bibliometric analysis of four sport management journals. Sport Management Review, 14(4), 434-452.

Skille, E. A. (2011). Change and isomorphism: A case of translation process in a Norwegian sport club. Sport Management Review, 14, 79-88.

Skinner, J., \& Edwards, A. (2005). Inventive pathways: Fresh visions of sport management research. Journal of Sport Management, 19, 404-421.

Skinner, J., Stewart, B., \& Edwards, A. (1999). Amateurism to professionalism: Modeling organisational change in sporting organisations. Sport Management Review, 2, 173-192.

Skinner, J., Zakus, D., \& Cowell, J. (2008). Development through sport: Building social capital in disadvantaged communities. Sport Management Review, 11, 253275.

Slack, T., \& Hinings, B. (1992). Understanding change in national sport organizations: An integration of theoretical perspectives. Journal of Sport Management, 6 , $114-132$.

Slack, T., \& Hinings, C. R. (1994). Institutional pressures and isomorphic change: An empirical test. Organization Studies, $15,803-827$.

Slack, T., \& Kikulis, L. M. (1989). The sociological study of sport organizations: Some observations on the situation in Canada. International Review for the Sociology of Sport, 24, 179-199. 
Spaaij, R. (2009). The glue that holds the community together? Sport and sustainability in rural Australia. Sport in Society, 12(9), 1132-1146.

Spaaij, R. (2012). Cultural diversity in community sport: An ethnographic inquiry of Somali Australians' experiences. Sport Management Review http://dx.doi.org/ 10.1016/j.smr.2012.06.003.

Stewart, B., Adair, D., \& Smith, A. C. T. (2011). Drivers of illicit drug-use regulation in Australian sport. Sport Management Review, 14, $237-245$.

Stevens, J. A., \& Slack, T. (1998). Integrating social action and structural constraints. Towards a more holistic explanation of organizational change. International Review for the Sociology of Sport, 33, 143-154.

Swartz, D. L. (2008). Bringing Bourdieu's master concepts into organizational analysis. Theory and Society, 37, 45-52.

Tatli, A. (2010). Towards an integrated relational theory of diversity management. Paper presented at the Academy of Management Annual Meeting.

Taylor, B., \& Garratt, D. (2010). The professionalisation of sports coaching: Relations of power, resistance and compliance. Sport, Education and Society, 15, 121-139.

Tonts, M. (2005). Competitive sport and social capital in rural Australia. Journal of Rural Studies, 21, 137-149.

Washington, M. (2004). Field approaches to institutional change: The evolution of the National Collegiate Athletic Association 1906-1995. Organization Studies, 25, 395-417.

Washington, M., \& Ventresca, M. J. (2008). Institutional contradictions and struggles in the formation of U.S. Collegiate Basketball, 1880-1938. Journal of Sport Management, 22, 30-49.

Washington, M., \& Patterson, K. D. W. (2011). Hostile takeover or joint venture: Connections between institutional theory and sport management research. Sport Management Review, 14, 1-12.

Woolcock, M. (2001). The place of social capital in understanding social and economic outcomes. Isuma: Canadian Journal of Policy Research, 2(1), 11-17.

Wright, A. L. (2009). Domination in organizational fields: It's just not cricket. Organization, 16, 855-885. 